\title{
Simulation of emergency events with fire in virtual road tunnels
}

\author{
Peter Danišovič ${ }^{1, *}$, Juraj Šrámek $^{1}$ and Michal Hodoñ ${ }^{2}$ \\ ${ }^{1}$ University of Žilina, Faculty of Civil Engineering, Univerzitná 8215/1, 01026 Žilina, Slovakia \\ ${ }^{2}$ University of Žilina, Faculty of Management Science and Informatics, Univerzitná 8215/1, 01026 \\ Žilina, Slovakia
}

\begin{abstract}
Road emergency events are very dangerous, especially if they happen in tunnels. If such an event occurs with the presence of fire, selfevacuation is the most important. From experience from catastrophic events in Alpine tunnels, people can only have a few minutes to rescue. It was also reason that a lot of changes in technology and safety tunnel equipment have been legislatively adopted. Then if we want to help rescue people, we need experienced tunnel operators, who know the principles of tunnel ventilation control with fire and smoke. This paper is about simulation of emergency events in virtual tunnel of Tunnel Traffic \& Operation Simulator (Simulator) and about simulations of smoke stratification on the basis of Computer Fluid Dynamics (CFD) models.
\end{abstract}

\section{Introduction}

Operational safety of road tunnels depends on many factors. The main factor is the behaviour of road tunnel users and then there are many factors, e.g. presence and condition of safety and technological equipment, experience and preparedness of tunnel operators and other parts of the rescue system. The correct choice of traffic-operation state and consistent optimal managing of emergency event are a key element to achieve successful solution of an event/incident. Simulator built from the project Centre of Transport Research creates the possibilities to simulate a variety of tunnel incidents. In cooperation with Institute of Informatics of Slovak Academy of Sciences we are preparing to expand Simulator (next year) on the most realistic visualizations of the smoke spread in case of a fire in the virtual road tunnel (Fig. 1).

\footnotetext{
* Corresponding author: peter.danisovic@ fstav.uniza.sk
} 


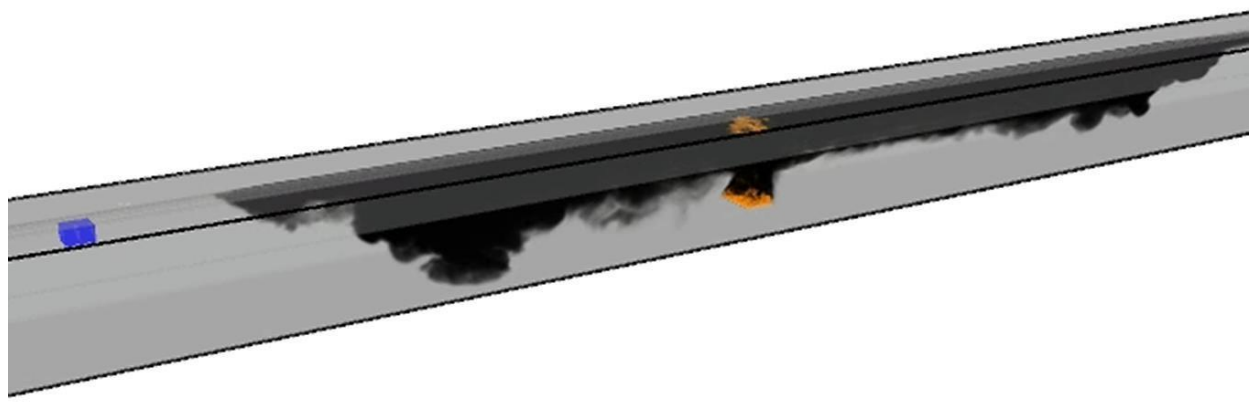

Frame: 228

$>200(\mathrm{~kW} / \mathrm{m} 3)$

Time: 57.0

Fig. 1. 3D visualization of smoke development in road tunnel.

\section{Simulator}

Simulator (Fig. 2) is a unique feature and new opportunity for research and education at the field of university and training of real road tunnel operators of Slovak tunnel administrator. The technology equipment of virtual tunnel, visualization of Central control system (CCS) and way of operation/control is in accordance with Slovak legislation from 2013. It allows simulate incidents which are rare in the real tunnel traffic with the aim of verification of correctness and philosophy of the tunnel operation.

Visualizations of the tunnel traffic and technology management are the same as on the real operator workplace of a two-tube tunnel. It is possible to control a virtual tunnel by two independent operators (for traffic and technology) and their work is changeable, so it means that single operator can control entire tunnel from his/her workstation. In contrast to real traffic, simulation of video surveillance shows a virtual traffic in the tunnel tubes and in front of them.

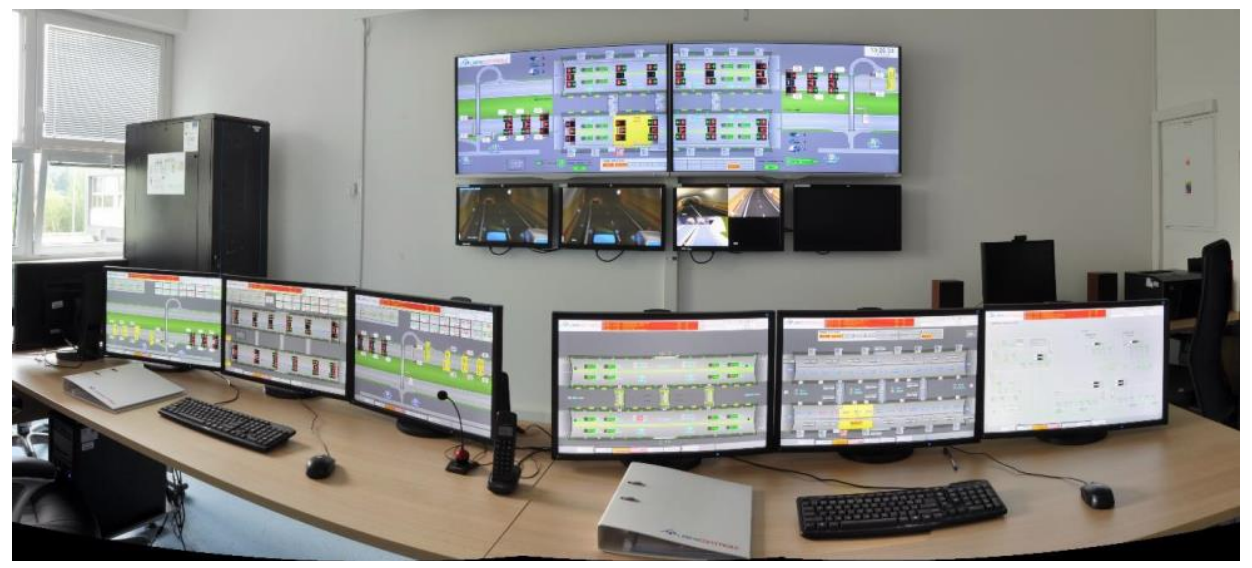

Fig. 2. Simulator's panoramic photo.

\section{Ventilation strategy}

Maintaining of smoke stratification is the main goal of ventilation system in case of fire in road tunnels. This task in bi-directional tunnels is not trivial. The smoke stratification exists under specific circumstances only and depends on many factors and can be easily disrupted. 
Proper jet fan ventilation strategy is a crucial precondition of efficient safety measures during fires in road tunnels. Procedure used in unidirectional tunnels is relatively straightforward. Jet fans create an air flow with critical velocity able to push smoke away from the tunnel and to prevent backlayering in upstream direction. It is called as critical flow velocity. Conditions downstream of the fire are usually untenable for human lives as critical velocity does not maintain smoke stratification and the tunnel tube is filled with smoke. However, it is assumed that people in that part of the tunnel can continue to drive and escape before conditions become untenable [1].

Situation is more complicated in bi-directional tunnels, where people are endangered by smoke on both sides of the fire and tenability conditions should be maintained long enough to ensure safe evacuation. The aim of the ventilation strategy is therefore to achieve prescribed target velocity of the flow maintaining stratification of smoke layer and thus tenable conditions for human life [1].

The main difficulty of this strategy is to determine a proper value of target velocity. Slovak regulations recommend 1.5 m.s-1 velocity [2], while Czech regulations recommend 1.2 m.s-1 velocity [3]. If the target velocity is set to some prescribed value, interaction with buoyancy forces created by the fire may lead to significantly higher flow velocity in some regions of the tunnel and smoke stratification in that part of the tunnel may not be maintained. Therefore, careful evaluation is needed to evaluate smoke movement in specific fire scenarios. This problem is of special importance in Slovakia, where several road tunnels with longitudinal ventilation are currently under construction, including some bi-directional tunnels [1]. Therefore, computer simulation of typical fire and ventilation scenarios can be considered as useful guide for tunnel management.

\section{Simulations}

In this chapter will be described different types of simulations created on Simulator and by colleagues from Institute of Informatics of Slovak Academy of Sciences.

\subsection{Emergency events}

There are a lot of possibilities to simulate various emergency events from position of coordinator, e.g. (Fig. 3):

- slowly moving vehicle forming tailback of cars in tunnel tube,

- breakdown of vehicle (stopped vehicle) and possibility to make an accident,

- animal in tunnel and possibility of collision,

- pedestrian in tunnel and possibility of collision,

- stopped heavy good vehicle (HGV) with dangerous goods (DG) and possibility of leakage or fire,

- lost cargo and possibility of collision or fire,

- leakage of chemical substance,

- demonstration of people in tunnel,

- threat of terrorist attack,

- vehicle in bad direction,

- oversized vehicle stopped in front of the tunnel portal,

- stopped bus and a lot of people moving in the tunnel,

- accident of two cars and possibility of fire (Fig. 3).

Emergency events mentioned above may be complemented by simulation of different standard and non-standard situations and technology equipment faults, for example: 
- changes of physical values (opacity/visibility, level of carbon monoxide, luminosity, temperature, speed of airflow) due to actual conditions,

- changes of traffic flow (sporadic, normal, tailbacks, stop and go),

- faults and breakdowns of tunnel technologic equipment (cameras, various detectors, traffic signs, power supply, local connections, etc.),

- changes of operational parameters (day, night, fog, smog),

- emergency calls (from SOS cabin, with tunnel specialists, integrated emergency rescue system, rescuers, fireman and many other responsible persons).

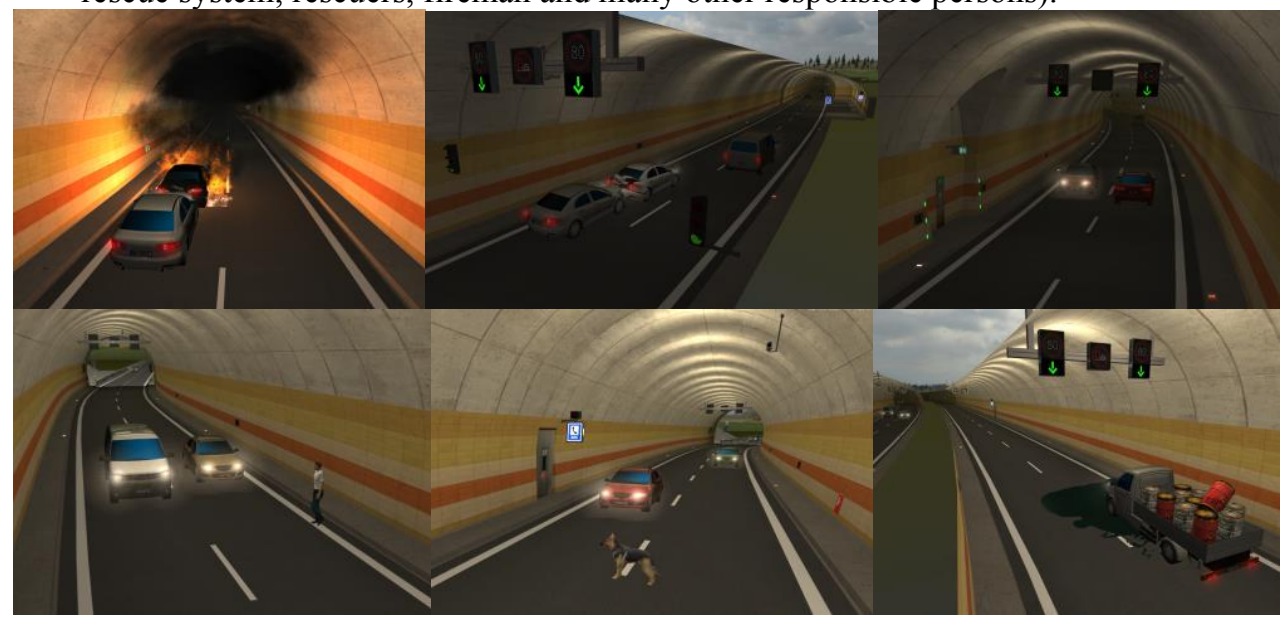

Fig. 3. Examples of simulated emergency events (accident of two cars with fire and without fire, vehicle in bad direction, pedestrian and animal in tunnel, stopped heavy good vehicle (HGV) with dangerous goods (DG) and leakage).

\subsection{Fire and smoke spread}

These simulations were carried out by colleagues from Slovak Academy of Sciences within the joint project titled "Models of formation and spread of fire to increase safety of road tunnels".

1. Impact of ventilation on smoke stratification in the Pol'ana tunnel, $900 \mathrm{~m}$ long tunnel with bi-directional operation and longitudinal ventilation of four couples of jet fans. Simulation of automobile file in the middle of the tunnel between two emergency laybys was created. Fig. 4 illustrates development of smoke and flow velocity at the $155^{\text {th }}$ second of fire. The ventilation was set in accordance with Slovak legislation regulations.

Fig. 4. Development of smoke (black and white picture) and flow velocity (red and blue colour represents the biggest and smallest values, respectively) at the $155^{\text {th }}$ second of fire simulation.

2. Tunnel Pol'ana has a slope of $2 \%$. In case the tunnel differs in variable slope ( $2 \%$ slope along the first $450 \mathrm{~m} ;-2 \%$ slope along the remaining $450 \mathrm{~m}$ ) very interesting results of simulations are illustrated (Fig. 5, 6). 
Fig. 5. Differences of smoke spread depending on the variable slope (second picture) [4].
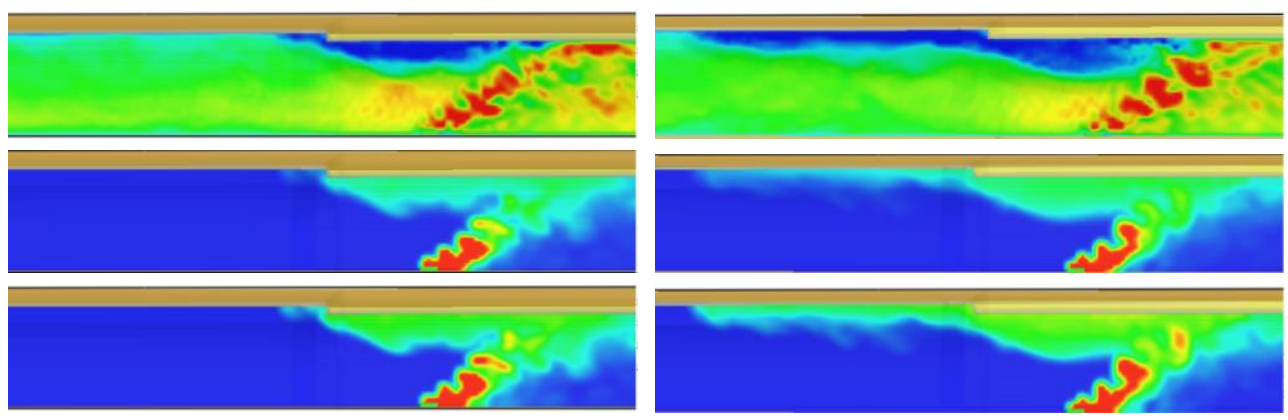

Fig. 6. $2 \mathrm{D}$ visualizations of airflow velocity, temperature and optical density depending on the variable slope (pictures at right side); colour schemes represent the values ranging from -0.52 to 4.40 $\mathrm{m} / \mathrm{s}$, from 4.78 to $198^{\circ} \mathrm{C}$ and from 0 to $3.92 / \mathrm{m}$, respectively, and the corresponding colour schemes for tunnel with variable slope represent the values ranging from -0.65 to $4.35 \mathrm{~m} / \mathrm{s}$, from 4.80 to $205^{\circ} \mathrm{C}$ and from 0 to $4 / \mathrm{m}$, respectively [4].

\section{Simulations}

Simulations on Tunnel Traffic \& Operation Simulator are very useful for real road tunnel operators to acquire skills to deal emergency events. Simulation showed that buoyancy force of fire accelerates the smoke spread in ascending tunnel, but in descending part of tunnel it slows down the smoke spread and reaches the tunnel portal 17 seconds later. Only limited backlayering can be observed in ascending tunnel. In tunnel with variable slope a more notable backlayering can be observed, however, its velocity is relatively low.

This work was supported by the Slovak Research and Development Agency APVV (project No. APVV-15-0340).

\section{References}

1. P. Weisenpacher, J. Glasa and L. Valasek, Computer simulation of smoke stratification during fire in bi-directional road tunnel by fds 6 , Tenth mediterranean combustion symposium, MCS 10, Naples, Italy (2017)

2. TP 12/2011 Road tunnels ventilation (in Slovak), Ministry of Transport and Construction of the Slovak Republic (2011)

3. Guideline - Road tunnels ventilation (in Czech), Ministry of Transport of the Czech Republic (2013)

4. P. Danisovic, J. Sramek, M. Hodon, J. Glasa, P. Weisenpacher, L. Valasek, Measurements and fire simulation models in road tunnels, MATEC Web of Conferences, 196, 04077 (2018) 